\title{
Serum oxidative stress is an independent prognostic marker in colorectal cancer
}

\author{
Kiichi Sugimoto, Kazuhiro Sakamoto, Masaya Kawai, Shingo Kawano, Shinya Munakata, Shun Ishiyama, \\ Makoto Takahashi, Yutaka Kojima, Yuichi Tomiki \\ Department of Coloproctological Surgery, Juntendo University Faculty of Medicine, Tokyo, Japan \\ Contributions: (I) Conception and design: K Sugimoto, K Sakamoto; (II) Administrative support: K Sakamoto, K Tomiki; (III) Provision of study \\ materials or patients: M Takahashi, Y Kojima; (IV) Collection and assembly of data: K Sugimoto, M Kawai, S Kawano, S Munakata, S Ishiyama; \\ (V) Data analysis and interpretation: K Sugimoto, K Sakamoto, S Ishiyama, K Kojima; (VI) Manuscript writing: All authors; (VII) Final approval of \\ manuscript: All authors. \\ Correspondence to: Kiichi Sugimoto. 2-1-1 Hongo Bunkyo-ku, Tokyo, Japan. Email: ksugimo@juntendo.ac.jp.
}

\begin{abstract}
Background: Few previous studies have investigated the relationship between serum oxidative stress and the status of patients with colorectal cancer. Our aim in the current study was to investigate the significance of serum oxidative stress as a prognostic marker in these patients.

Methods: The subjects were 53 patients who underwent curative resection of high-risk stage II or stage III colorectal cancer. The correlation of serum oxidative stress (Reactive Oxygen Metabolites Test: d-ROMs Test) with recurrence-free survival was examined.

Results: There were no significant differences in d-ROMs between the recurrence and non-recurrence groups at four time points (0M: before the start of postoperative adjuvant chemotherapy; and 1M: 1 month; 3M: 3 months; and 6M: 6 months after the start of postoperative adjuvant chemotherapy). Only the $3 \mathrm{M} / 0 \mathrm{M}$ d-ROMs (the value at $3 \mathrm{M}$ relative to the value at $0 \mathrm{M}$ ) was increased compared with the other time points in the recurrence group, as well as with all time points in the non-recurrence group. In univariate analysis, there were significant differences in recurrence-free survival with respect to $\mathrm{N}$ classification $(\mathrm{P}=0.004)$ and $3 \mathrm{M} / 0 \mathrm{M}$ d-ROMs $(\mathrm{P}=0.002)$. In multivariate analysis, both $\mathrm{N}$ classification and serum oxidative stress were found to be significant independent prognostic factors $(\mathrm{P}=0.02, \mathrm{HR}=4.49 ; \mathrm{P}=0.02, \mathrm{HR}=5.61$, respectively).
\end{abstract}

Conclusions: The results of this study demonstrate the prognostic value of serum oxidative stress in colorectal cancer.

Keywords: Colorectal cancer; prognostic factor; serum oxidative stress

Submitted Oct 01, 2018. Accepted for publication Jul 30, 2019.

doi: $10.21037 /$ tcr.2019.08.15

View this article at: http://dx.doi.org/10.21037/tcr.2019.08.15

\section{Introduction}

Colorectal cancer is one of the most common causes of cancer death worldwide, and its incidence in Japan is increasing rapidly $(1,2)$. The long-term outcomes in patients with colorectal cancer have improved over the past two decades (3). Follow-up surveillance after surgery for colorectal cancer is usually conducted with predictive markers, such as blood CEA levels $(4,5)$. Since these markers reflect tumor development or progression, most of the clinically applied markers are tumor-oriented. On the other hand, patient-oriented predictive markers, such as the performance status (PS), the American Society of Anesthesiologists (ASA) score or prognostic nutrition index (PNI) have also been reported (6-8).

Recently, it has been reported that serum oxidative stress plays an important role in the development and progression of human cancers $(9,10)$. Some reports have suggested that high levels of serum oxidative stress are associated with poor prognoses in chronic lymphocytic leukemia or lung cancer 
$(11,12)$. However, few previous studies have investigated the relationship between serum oxidative stress and the status of colorectal cancer patients.

We hypothesize that serum oxidative stress is an indicator of prognosis in colorectal cancer. Our aim in the current study was to investigate the significance of serum oxidative stress as a prognostic marker in colorectal cancer patients after curative resection.

\section{Methods}

\section{Study population}

The subjects were 53 patients who underwent curative resection of high-risk stage II or stage III colorectal cancer between 2008 and 2010, and were subjects in an earlier study (13). Based on the ASCO recommendations (14), high-risk stage II was defined as the disease with high grade differentiation, $\mathrm{T} 4$ disease, inadequate lymph node harvesting ( $<12$ lymph nodes dissected), preoperative ileus or perforation. The inclusion criteria were an Eastern Cooperative Oncology Group PS of 0,1 or 2, age $<80$ years old, and no synchronous or metachronous multiple cancers. No subjects received preoperative adjuvant chemotherapy or chemoradiotherapy because these treatments were not widely accepted for use in colorectal cancer in Japan during the study period. Patients received Tegafur/uracil (UFT; Taiho ${ }^{\circledR}$, Japan) $\left(300 \mathrm{mg} / \mathrm{m}^{2} /\right.$ day) and Leucovorin (LV; Taiho ${ }^{\circledR}$, Japan) (75 mg/day) with or without Polysaccharide-Kureha (PSK; Kureha ${ }^{\circledR}$, Japan) (3.0 g/day) daily as postoperative adjuvant chemotherapy, starting 4 to 8 weeks after surgery, and continuing for six months or until tumor recurrence (13). UFT/LV was administered for 5 consecutive days, followed by 2 days without administration of the drugs (13). Database and medical records were reviewed retrospectively. The study was approved by the institutional review board of Juntendo University Hospital (No. 17-178).

\section{Examination content}

Background data, clinicopathological factors and serum oxidative stress were analyzed. Serum oxidative stress was measured using a Reactive Oxygen Metabolites (d-ROMs) Test. The d-ROMs Test measures the hydroperoxide concentration using the FRAS4 Free Radical Analytical System (Wismerll Co., Tokyo, Japan). This test was performed as described previously $(15,16)$. Briefly, the d-ROMs test was performed with fresh serum immediately after blood collection. In this test, hydroperoxides released from proteins in serum are catalyzed by transition metals to form free radicals that are trapped by an alchilamine, which results in increased absorbance at $505 \mathrm{~nm}$. The optical density of the photometrically colored complex that is formed is directly proportional to the concentration of hydroperoxides. The results are expressed in arbitrary units "U.CARR", and the reference range is 250-300 U.CARR. A d-ROMs value $\geq 300$ U.CARR suggests serum oxidative stress due to abnormal production of free radicals. Serum oxidative stress using the $\mathrm{d}-\mathrm{ROMs}$ test and adverse events were monitored for 6 months during postoperative adjuvant chemotherapy in our previous study (13). Therefore, the d-ROMs test was performed before and 1, 3 and 6 months after the start of postoperative adjuvant chemotherapy in this study.

\section{Statistical analysis}

A Fisher exact probability test was used to compare discrete variables. Continuous variables were compared by MannWhitney U-test for individual comparisons and Wilcoxon signed rank test for paired comparisons. Spearman rank correlation coefficient analysis was used to estimate correlations of continuous variables between two groups. The Kaplan-Meier method was used to calculate recurrence-free survival, and univariate analyses were performed by log-rank test. Clinicopathological factors with significant differences in univariate analysis were used as covariates in multivariate analysis, using a Cox proportional-hazard regression model with $95 \%$ confidence intervals. The area under the receiver operating curve (AUROC) was used to determine a cut-off value for the d-ROMs Test. The value obtained when the AUROC was largest was defined as the cut-off value. JMP 9 software (SAS Institute Inc., Cary, NC, USA) was employed to analyze the data. Statistical significance was set at $\mathrm{P}<0.05$. Values are expressed as the median (range).

\section{Results}

\section{Patient characteristics}

The patient characteristics are shown in Table 1 . Preoperative morbidities were observed in 38 patients (71.7\%). Postoperative complications (Clavian-Dindo; all grades) were observed in 13 patients (24.5\%). Recurrence was detected in 12 patients (22.6\%), including in the liver in 7 patients $(13.2 \%)$, lung in 3 patients $(5.7 \%)$, para- 
Table 1 Patient characteristics

\begin{tabular}{|c|c|}
\hline Clinicopathological factors & Value $(\mathrm{N}=53)$ \\
\hline Age, years, median [range] & $65[37-78]$ \\
\hline \multicolumn{2}{|l|}{ Gender, n (\%) } \\
\hline Male & $30(56.6)$ \\
\hline Female & $23(43.4)$ \\
\hline \multicolumn{2}{|l|}{ Location, n (\%) } \\
\hline Colon & $38(71.7)$ \\
\hline Rectum & $15(28.3)$ \\
\hline \multicolumn{2}{|l|}{ Preoperative morbidity, n (\%) } \\
\hline Present & $38(71.7)$ \\
\hline Absent & $15(28.3)$ \\
\hline \multicolumn{2}{|l|}{ Procedure, n (\%) } \\
\hline Open & $22(41.5)$ \\
\hline Laparoscopic & $31(58.5)$ \\
\hline \multicolumn{2}{|l|}{ Postoperative complication, n (\%) } \\
\hline Present & $13(24.5)$ \\
\hline Absent & $40(75.5)$ \\
\hline \multicolumn{2}{|l|}{ Differentiation, n (\%) } \\
\hline Well differentiated adenocarcinoma & $9(17.0)$ \\
\hline Moderately differentiated adenocarcinoma & $39(73.6)$ \\
\hline Poorly differentiated adenocarcinoma & $3(5.7)$ \\
\hline Mucinous adenocarcinoma & $2(3.8)$ \\
\hline \multicolumn{2}{|l|}{ Stage, n (\%) } \\
\hline II & $7(13.2)$ \\
\hline III & $46(86.8)$ \\
\hline \multicolumn{2}{|l|}{ Recurrence forms ${ }^{*}, \mathrm{n}(\%)$} \\
\hline Liver & $7(13.2)$ \\
\hline Lung & $3(5.7)$ \\
\hline Para-aortic lymph node & $2(3.8)$ \\
\hline Local (intrapelvic) & $1(1.9)$ \\
\hline Peritoneum & $1(1.9)$ \\
\hline
\end{tabular}

*, with some duplication.

aortic lymph node in 2 patients (3.8\%), local (intrapelvic) in 1 patient $(1.9 \%)$ and peritoneum in 1 patient $(1.9 \%)$. Some patients had multiple recurrences. The median observation period for survivors was 81.1 months (range, 12.5106.2 months).

\section{d-ROMs test}

There were no significant differences in the d-ROMs between the recurrence and non-recurrence groups at the four time points (before the start of postoperative adjuvant chemotherapy; $0 M, 1$ month; $1 M$, 3 months; $3 M$ and 6 months; $6 \mathrm{M}$ after the start of postoperative adjuvant chemotherapy) ( $\mathrm{P}=0.75,0.74,0.50$ and 0.94 , respectively) (Figure 1). Next, we compared the serial changes of the d-ROMs, with $0 M$ as the standard. Serial changes in the relative d-ROMs are shown in Figure 2. Similarly, there were no significant differences in the relative $\mathrm{d}-\mathrm{ROMs}$ between the two groups at the three time points (i.e., the values at each point relative to the values at $0 \mathrm{M})(1 \mathrm{M} / 0 \mathrm{M}$ : $\mathrm{P}=0.84$, $3 \mathrm{M} / 0 \mathrm{M}: 0.42$ and $6 \mathrm{M} / 0 \mathrm{M}: 0.90)$. Only the $3 \mathrm{M} / 0 \mathrm{M}$ d-ROMs was increased compared with the other time points in the recurrence group, as well as with all time points in the nonrecurrence group. There were also no significant differences in the relative d-ROMs between stages II and III at the three time points (i.e., values at each point relative to the value at $0 \mathrm{M})(1 \mathrm{M} / 0 \mathrm{M}: \mathrm{P}=0.94,3 \mathrm{M} / 0 \mathrm{M}: \mathrm{P}=0.58$ and $6 \mathrm{M} / 0 \mathrm{M}: \mathrm{P}=0.65)$.

\section{Cut-off value for the d-ROMs test}

Since there were no significant differences in the d-ROMs between the two groups at each time point, we attempted to determine which time point would be optimal to predict long-term outcomes. To determine which time point was optimal relative to recurrence-free survival, AUROCs were calculated for the relative d-ROMs findings. The AUROCs were $0.5305(0 \mathrm{M}), 0.5315(1 \mathrm{M}), 0.5640(3 \mathrm{M}), 0.5081(6 \mathrm{M})$, $0.5183(1 \mathrm{M} / 0 \mathrm{M}), 0.5772(3 \mathrm{M} / 0 \mathrm{M})$ and $0.5135(6 \mathrm{M} / 0 \mathrm{M})$. Consequently, AUROC was largest when the $3 \mathrm{M} / 0 \mathrm{M} \mathrm{d}-\mathrm{ROMs}$ finding was used. Thus, for a cut-off value for $3 \mathrm{M} / 0 \mathrm{M} \mathrm{d}-\mathrm{ROMs}$ of 1.458 , the odds ratio relative to recurrence-free survival was the largest. Therefore, the cut-off value was defined as the $3 \mathrm{M} / 0 \mathrm{M}$ d-ROMs value of 1.458 , and patients were categorized into two groups: 47 in the low group $(3 \mathrm{M} / 0 \mathrm{M} \mathrm{d}-\mathrm{ROMs}$ $<1.458)$ and 6 in the high group $(3 \mathrm{M} / 0 \mathrm{M} \mathrm{d}-\mathrm{ROMs} \geq 1.458)$.

\section{Comparisons of clinicopathological factors between the low and bigh groups}

In univariate analysis, there were no significant differences in clinicopathological factors between the low and high groups (Table 2). There were no significant correlations between $3 \mathrm{M} / 0 \mathrm{M} \mathrm{d}-\mathrm{ROMs}$ and CEA values preoperatively, and at $0 \mathrm{M}, 1 \mathrm{M}$, and $3 \mathrm{M}(\mathrm{P}=0.94,0.80,0.72$ and 0.46 , 

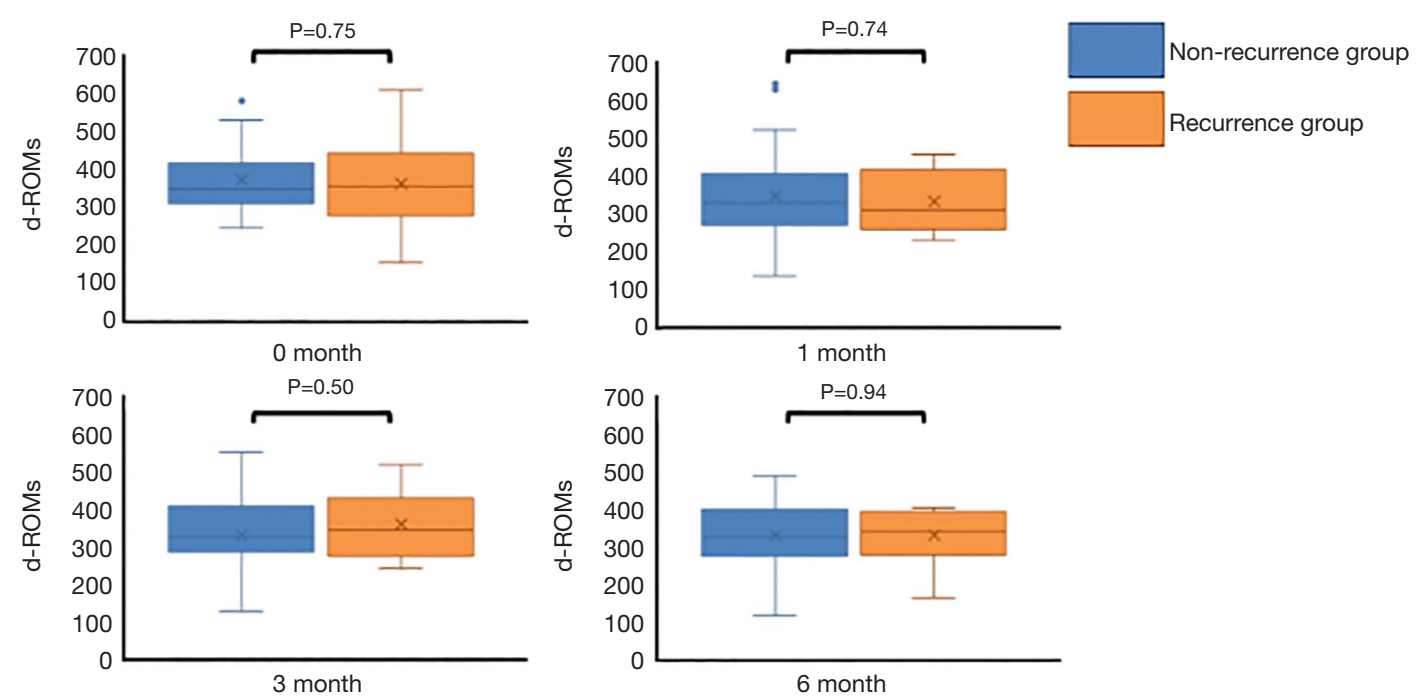

Figure 1 Comparison of d-ROMs values between the recurrence and non-recurrence groups at four time points. There was no significant difference in $\mathrm{d}-\mathrm{ROM}$ s between the two groups at each time point $(\mathrm{P}=0.75,0.74,0.50$ and 0.94 , respectively).

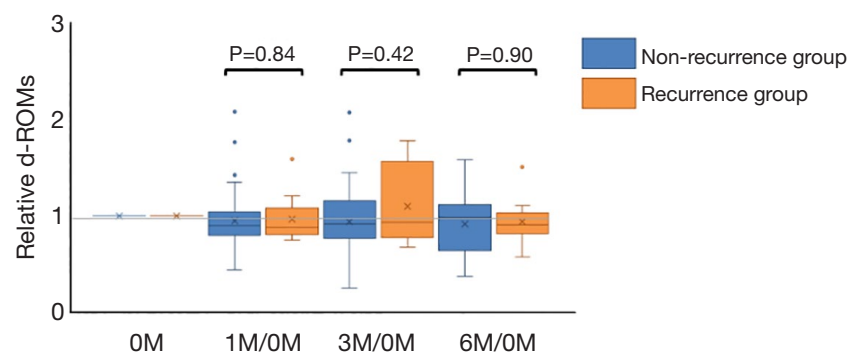

Figure 2 Serial changes in the relative d-ROMs. There was no significant difference in the relative $\mathrm{d}-\mathrm{ROMs}$ between the two groups at each of the three time points: $1 \mathrm{M} / 0 \mathrm{M}$ : $\mathrm{P}=0.84,3 \mathrm{M} / 0 \mathrm{M}$ : $\mathrm{P}=0.42,6 \mathrm{M} / 0 \mathrm{M}: \mathrm{P}=0.90$.

respectively) (Figure 3).

\section{Prognostic factors related to recurrence-free survival}

Comparisons of recurrence-free survival rates according to clinicopathological factors and $3 \mathrm{M} / 0 \mathrm{M} \mathrm{d}-\mathrm{ROMs}$ are shown in Table 3. In univariate analysis, only $\mathrm{N}$ classification $(\mathrm{P}=0.004)$ and $3 \mathrm{M} / 0 \mathrm{M}$ d-ROMs $(\mathrm{P}=0.002)$ had significant associations with recurrence-free survival. In multivariate analysis with these two factors used as covariates, both $\mathrm{N}$ classification $(\mathrm{P}=0.02 ; \mathrm{HR}=4.49)$ and $3 \mathrm{M} / 0 \mathrm{M} \mathrm{d}-\mathrm{ROMs}(\mathrm{P}=0.02 ; \mathrm{HR}=5.61)$ were found to be significant independent prognostic factors (Table 4). Recurrence-free survival curves for each factor are shown in Figure 4. Recurrence-free survival in N2 cases was
Table 2 Comparison of clinicopathological factors between the low and high groups for 3M/0M d-ROMs

\begin{tabular}{|c|c|c|c|}
\hline \multirow{2}{*}{$\begin{array}{l}\text { Clinicopathological } \\
\text { factors }\end{array}$} & \multicolumn{2}{|c|}{ 3M/OM d-ROMs } & \multirow[b]{2}{*}{$\mathrm{P}$ value } \\
\hline & $\begin{array}{l}\text { Low group } \\
\qquad(n=47)\end{array}$ & $\begin{array}{l}\text { High group } \\
\qquad(n=6)\end{array}$ & \\
\hline Age & 65 [37-78] & $62[57-78]$ & 0.90 \\
\hline Gender & & & 0.69 \\
\hline Male & 26 & 4 & \\
\hline Female & 21 & 2 & \\
\hline Current smoking & & & 0.31 \\
\hline Present & 8 & 2 & \\
\hline Absent & 39 & 4 & \\
\hline Location & & & 0.66 \\
\hline Colon & 33 & 5 & \\
\hline Rectum & 14 & 1 & \\
\hline Preoperative morbidity & & & 0.17 \\
\hline Present & 32 & 6 & \\
\hline Absent & 15 & 0 & \\
\hline Preoperative CEA & $3.3(0.6-48.5)$ & $6.5(0.9-14.6)$ & 0.33 \\
\hline Procedure & & & 1.00 \\
\hline Open & 20 & 2 & \\
\hline Laparoscopic & 27 & 4 & \\
\hline
\end{tabular}

Table 2 (continued) 
Table 2 (continued)

\begin{tabular}{|c|c|c|c|}
\hline \multirow{2}{*}{$\begin{array}{l}\text { Clinicopathological } \\
\text { factors }\end{array}$} & \multicolumn{2}{|c|}{$3 \mathrm{M} / 0 \mathrm{M} \mathrm{d}-\mathrm{ROMs}$} & \multirow[b]{2}{*}{$P$ value } \\
\hline & $\begin{array}{l}\text { Low group }^{\dagger} \\
\qquad(\mathrm{n}=47)\end{array}$ & $\begin{array}{l}\text { High group }{ }^{\ddagger} \\
\qquad(n=6)\end{array}$ & \\
\hline \multicolumn{2}{|c|}{ Postoperative complication } & & 1.00 \\
\hline Present & 12 & 1 & \\
\hline Absent & 35 & 5 & \\
\hline \multicolumn{2}{|l|}{ Differentiation } & & 0.47 \\
\hline Differentiated $^{\S}$ & 43 & 5 & \\
\hline Undifferentiated" & 4 & 1 & \\
\hline \multicolumn{2}{|l|}{ T classification } & & 1.00 \\
\hline T1-T3 & 40 & 5 & \\
\hline $\mathrm{T} 4$ & 7 & 1 & \\
\hline \multicolumn{2}{|l|}{ Lymphatic invasion } & & 0.39 \\
\hline None-mild & 44 & 5 & \\
\hline Moderate-severe & 3 & 1 & \\
\hline \multicolumn{2}{|l|}{ Venous invasion } & & 0.65 \\
\hline None-mild & 32 & 5 & \\
\hline Moderate-severe & 15 & 1 & \\
\hline \multicolumn{2}{|l|}{ Stage } & & 1.00 \\
\hline II & 6 & 1 & \\
\hline III & 41 & 5 & \\
\hline \multicolumn{2}{|l|}{$\mathrm{N}$ classification } & & 1.00 \\
\hline No, 1 & 39 & 5 & \\
\hline N2 & 8 & 1 & \\
\hline \multicolumn{3}{|c|}{$\begin{array}{l}\text { Completion of postoperative adjuvant } \\
\text { chemotherapy }\end{array}$} & 0.47 \\
\hline Present & 43 & 5 & \\
\hline Absent & 4 & 1 & \\
\hline
\end{tabular}

†, 3M/OM d-ROMs <1.458; ${ }^{\ddagger}, 3 \mathrm{M} / 0 \mathrm{M}$ d-ROMs $\geq 1.458$; ${ }^{\S}$, wellor moderately-differentiated adenocarcinoma; ", poorlydifferentiated or mucinous adenocarcinoma.

significantly worse than that in $\mathrm{N} 0$ or $\mathrm{N} 1$ cases $(\mathrm{P}=0.004)$ and in patients in the high $3 \mathrm{M} / 0 \mathrm{M} \mathrm{d}-\mathrm{ROMs}$ group compared to those in the low $3 \mathrm{M} / 0 \mathrm{M}$ d-ROMs group $(\mathrm{P}=0.002)$.

\section{Discussion}

Oxidative stress is the consequence of overproduction of free radicals in mitochondria, such as reactive oxygen species (ROS) (17). Accumulation of oxidative stress leads to harmful effects on lipids, proteins, and DNA (17). ROS caused by oxidative stress are found in most cancers due to highly accelerated metabolism, and may promote aggressive phenotypes of tumor cells (18). Cancer cells can maintain ROS levels and avoid cell death (19), and ROS promote a sequence of tumor development and progression through these aggressive phenotypes (20). In normal cells, tumor suppressor genes (TSGs) control an increase in oxidative stress and maintain the oxidationreduction balance to prevent oxidative damage to DNA and proteins (20). This protective effect partly occurs due to hypomethylated anti-oxidative genes, as well as upregulated pro-apoptotic genes (21).

The absence of TSGs can lead to ROS accumulation because cancer cells switch off anti-oxidative pathways (22). Oncogenes also play a crucial role in controlling the ROS balance, and upregulation of other oncogenes may block the effects of TSGs and promote overproduction of ROS (23). Therefore, ROS can induce factors that promote epithelial-mesenchymal transition (EMT), which leads to tumor invasion and metastasis (24). ROS production in cancer cells also enhances metabolic adaptation to tumor microenvironments, which leads to proliferation and angiogenesis (25), and in pancreatic ductal carcinoma, increased ROS has both pro-survival and anti-apoptotic effects (26). However, the relationship between oxidative stress at the serum level and the status of colorectal cancer patients remains unclear (10). Therefore, we analyzed the clinical significance of serum oxidative stress in colorectal cancer.

The d-ROMs test detects derivatives of reactive oxygen metabolites (27). The principle of the test is that a lowered $\mathrm{pH}$ releases iron from serum proteins, which leads to degradation of hydroperoxides into free radicals through the Fenton reaction (28). The d-ROMs test is simple, quick, and requires only a minimal volume of sample (29). Therefore, the test has become increasingly popular (30) and has been used as a global indicator of serum oxidative stress in metabolic diseases such as atherosclerosis, hypertension, and diabetes $(27,31,32)$. Recently, the d-ROMs test has also been applied in cancer research (11,33-35). D'Arena and colleagues (11) reported that elevated d-ROMs in chronic lymphocytic leukemia (CLL) was likely to reflect reduced survival. In lung cancer, Tsukioka and colleagues (33) reported that d-ROMs was a significant predictive factor for nodal involvement in Stage I lung cancer. Katsabeki-Katsafli 

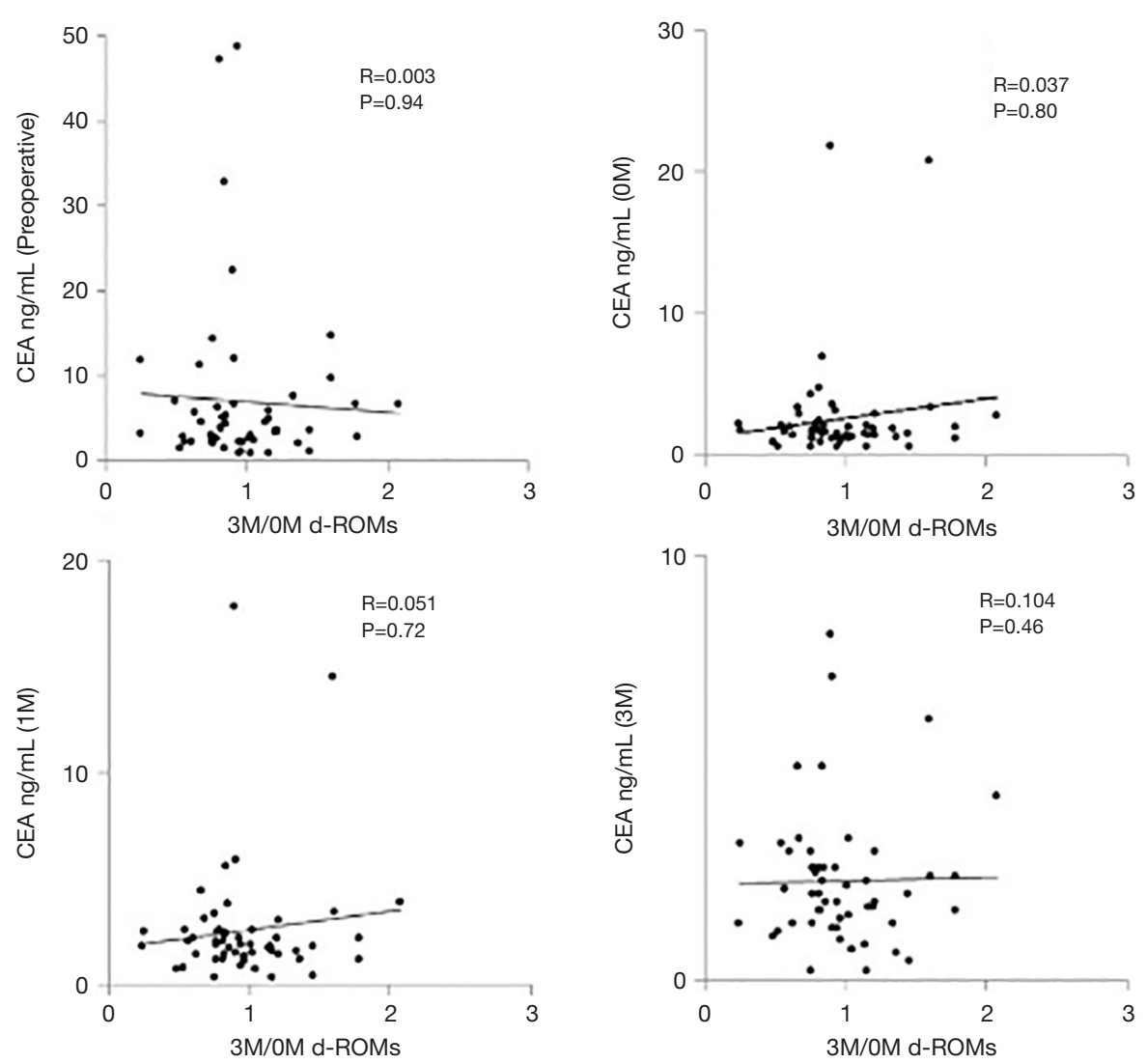

Figure 3 The correlations between the 3M/0M d-ROMs and CEA. There was no significant correlation between 3M/0M d-ROMs and CEA values preoperatively, and at $0 \mathrm{M}, 1 \mathrm{M}$, and $3 \mathrm{M}(\mathrm{P}=0.94,0.80,0.72$, and 0.46 , respectively).

and colleagues (34) showed that serum vascular endothelial growth factor was significantly correlated with serum oxidative stress in patients with lung cancer and concluded that this correlation might imply new mechanisms controlling tumor angiogenesis in lung cancer.

In colorectal cancer, there have been no reports relating d-ROMs to cancer progression. This may be because the results of the d-ROMS test vary both intra- and interindividually, as well as among clinical stages. For this reason, in the current study we limited the subjects to patients with similar stages, i.e., stage II and III, and with an identical postoperative adjuvant chemotherapy regimen. In fact, chemotherapy has been reported to affect serum oxidative stress in cancer patients (35). Furthermore, since there was no significant difference in the d-ROMs test between the recurrence and non-recurrence groups at each time point, we divided the d-ROMS values at each time point $(1 \mathrm{M}, 3 \mathrm{M}$, etc.) by the values at $0 \mathrm{M}$. Subsequently, the $3 \mathrm{M} / 0 \mathrm{M} \mathrm{d}-\mathrm{ROMs}$ value was found to be a significant independent prognostic factor. In this respect, our study is the first to demonstrate the prognostic significance of $\mathrm{d}-\mathrm{ROM}$ in patients with colorectal cancer. However, the reason why the $3 \mathrm{M} / 0 \mathrm{M}$ value was the most significant remains unclear. The $3 \mathrm{M} / 0 \mathrm{M}$ values may reflect invisible cancer cells remaining inside the body after macroscopically curative resection. Alternatively, differences in serum oxidative stress levels may reflect inherent differences in physiology independent of the tumor type; i.e. certain patients may have higher serum oxidative stress that then leads to a higher recurrence rate, rather than a particular tumor type causing this process. In either case, it is important to determine the optimal time point to evaluate d-ROMs for prognostic significance after curative surgery in colorectal cancer.

Interestingly, there were no significant correlations between d-ROMs values and background and clinicopathological factors, including current smoking status. This finding is similar to previous studies in lung cancer $(33,36)$. Moreover, 
Table 3 Comparisons of recurrence-free survival rates according to clinicopathological factors and $3 \mathrm{M} / 0 \mathrm{M} \mathrm{d}-\mathrm{ROMs}$

\begin{tabular}{|c|c|c|c|}
\hline Clinicopathological factors & $n$ & $\begin{array}{l}\text { 5-years recurrence- } \\
\text { free survival }(\%)\end{array}$ & $P$ value \\
\hline Age (years) & & & 0.67 \\
\hline$<75$ & 47 & 78.2 & \\
\hline$\geq 75$ & 6 & 83.3 & \\
\hline Gender & & & 0.85 \\
\hline Male & 30 & 79.4 & \\
\hline Female & 23 & 78.3 & \\
\hline Location & & & 0.63 \\
\hline Colon & 38 & 78.5 & \\
\hline Rectum & 15 & 80.0 & \\
\hline Preoperative morbidity & & & 0.65 \\
\hline Present & 38 & 75.7 & \\
\hline Absent & 15 & 86.7 & \\
\hline Procedure & & & 0.90 \\
\hline Open & 22 & 77.0 & \\
\hline Laparoscopic & 31 & 80.2 & \\
\hline Postoperative complication & & & 0.87 \\
\hline Present & 13 & 84.6 & \\
\hline Absent & 40 & 76.9 & \\
\hline Differentiation & & & 0.35 \\
\hline Differentiated $^{\dagger}$ & 48 & 80.8 & \\
\hline Undifferentiated $^{\ddagger}$ & 5 & 60.0 & \\
\hline T classification & & & 0.92 \\
\hline T1-T3 & 45 & 79.5 & \\
\hline $\mathrm{T} 4$ & 8 & 75.0 & \\
\hline Lymphatic invasion & & & 0.16 \\
\hline None-mild & 49 & 81.2 & \\
\hline Moderate-severe & 4 & 50.0 & \\
\hline Venous invasion & & & 0.28 \\
\hline None-mild & 37 & 75.1 & \\
\hline Moderate-severe & 16 & 87.5 & \\
\hline Stage & & & 0.15 \\
\hline II & 7 & 100.0 & \\
\hline III & 46 & 75.6 & \\
\hline
\end{tabular}

Table 3 (continued)
Table 3 (continued)

\begin{tabular}{lrcc}
\hline Clinicopathological factors & $\mathrm{n}$ & $\begin{array}{c}\text { 5-years recurrence- } \\
\text { free survival (\%) }\end{array}$ & P value \\
\hline N classification & & & 0.004 \\
N0, 1 & 44 & 86.0 & \\
N2 & 9 & 44.4 &
\end{tabular}

Completion of postoperative adjuvant chemotherapy $\quad 0.79$

\begin{tabular}{lccc} 
Present & 48 & 78.7 & \\
Absent & 5 & 80.0 & 0.002 \\
3M/OM d-ROMs & & & \\
Low group & \\
High group" & 47 & 84.8 & 25.0 \\
\hline${ }^{\dagger}$, well-differentiated adenocarcinoma; ${ }^{\ddagger}$, poorly-differentiated or \\
mucinous adenocarcinoma; ${ }^{\S}, 3 \mathrm{M} / 0 \mathrm{M}$ d-ROMs $<1.458 ; ~$ \\
d-ROMs $\geq 1.458$.
\end{tabular}

Table 4 Prognostic factors related to recurrence-free survival using a Cox proportional-hazard regression model

\begin{tabular}{lcccc}
\hline $\begin{array}{l}\text { Clinicopathological } \\
\text { factors }\end{array}$ & Variables & P value & $\begin{array}{c}\text { Hazard } \\
\text { ratio }\end{array}$ & $\begin{array}{c}95 \% \\
\text { confidence } \\
\text { intervals }\end{array}$ \\
\hline N classification & $\mathrm{N} 2$ & 0.02 & 4.49 & $1.31-14.35$ \\
$3 \mathrm{M} / 0 \mathrm{M}$ d-ROMs & High group $^{\dagger}$ & 0.02 & 5.61 & $1.43-19.49$ \\
\hline${ }^{\dagger}, 3 \mathrm{M} / 0 \mathrm{M}$ d-ROMs $\geq 1.458$. & & &
\end{tabular}

there were no significant correlations between d-ROMs and CEA levels at any time point, including preoperative values. According to these findings, serum oxidative stress status, as determined by the d-ROMs test, is an independent factor that could reflect a recurrence-favored environment in vivo, independent of clinicopathological factors, including serum CEA levels, and treatment-related factors. However, further investigation is needed to confirm this finding. In addition, we do not know whether these findings indicate a cause or a consequence of increased oxidative stress; that is, the phenomenon observed herein may reflect an enhanced tendency to develop recurrence under the influence of increased serum oxidative stress, or increased serum oxidative stress may be a consequence of recurrent disease. These theories appear to be one and indivisible.

Finally, there are several limitations in this study that are partly inherent to retrospective studies. First, the data were collected at a single institute and only a small number 

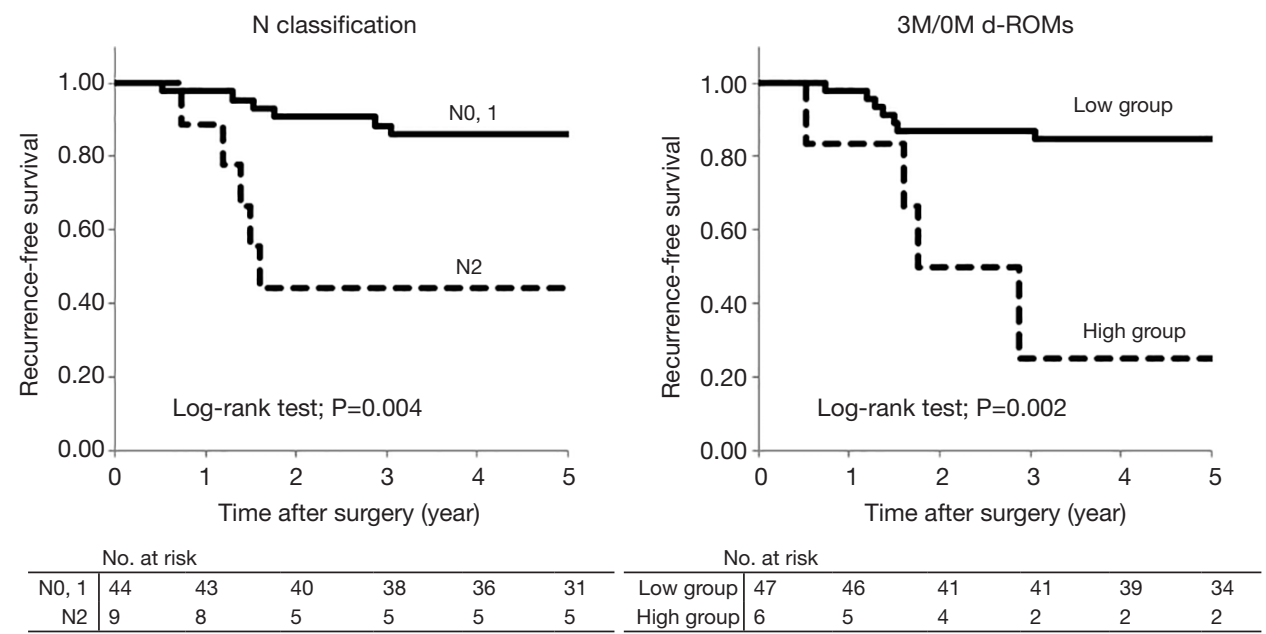

Figure 4 Recurrence-free survival curves. Recurrence-free survival in N2 cases was significantly worse than that in N0 or N1 cases (P=0.004), and in patients in the high 3M/0M d-ROMs group compared to those in the low 3M/0M d-ROMs group $(\mathrm{P}=0.002)$.

of cases were investigated, without a validation cohort. It is clear that a validation study with a different patient cohort will be necessary to confirm whether serum oxidative stress is an independent prognostic marker in colorectal cancer. Therefore, a prospective validation study with a sufficiently large cohort to investigate the prognostic capability of the $\mathrm{d}$-ROMs test is anticipated in the future. Second, the optimal cut-off values for the d-ROMs test may vary among study cohorts and with study goals. Third, we did not measure d-ROMs preoperatively because we initially aimed to evaluate serum oxidative stress that could result from postoperative adjuvant chemotherapy, as in our previous study (13). If serum oxidative stress were to reflect the status of patients in terms of the tendency for recurrence, the preoperative measurement of d-ROMs would be interesting. Finally, we did not have detailed information with respect to food intake or antioxidant supplements that could influence d-ROMs values. A previous study showed that the d-ROMs test is easily affected by lifestyle; i.e., food (37). In contrast, postoperative adjuvant chemotherapy in this study was consistent in all patients and did not influence the d-ROMs values (13).

Ras mutations have been reported to result in upregulation of oxidative stress in cancer cells (38). Patients with stage IV colorectal cancer are more likely to be affected by increased oxidative stress. Therefore, it will be interesting to study the relationship between serum oxidative stress and response to chemotherapy. Since ROS contribute to proliferation and survival of many cancers, inhibition of increased ROS production may be a promising future therapeutic strategy (23).

\section{Conclusions}

This study demonstrated the prognostic capability of serum oxidative stress in colorectal cancer. A prospective validation study in a large cohort of patients with colorectal cancer is needed to further validate these findings.

\section{Acknowledgments}

Funding: None.

\section{Footnote}

Conflicts of Interest: All authors have completed the ICMJE uniform disclosure form (available at http://dx.doi. org/10.21037/tcr.2019.08.15). The authors have no conflicts of interest to declare.

Ethical Statement: The authors are accountable for all aspects of the work in ensuring that questions related to the accuracy or integrity of any part of the work are appropriately investigated and resolved. The study was conducted in accordance with the Declaration of Helsinki (as revised in 2013). The study was approved by the institutional review board of Juntendo University Hospital (No. 17-178). The informed consent was waived.

Open Access Statement: This is an Open Access article 
distributed in accordance with the Creative Commons Attribution-NonCommercial-NoDerivs 4.0 International License (CC BY-NC-ND 4.0), which permits the noncommercial replication and distribution of the article with the strict proviso that no changes or edits are made and the original work is properly cited (including links to both the formal publication through the relevant DOI and the license). See: https://creativecommons.org/licenses/by-nc-nd/4.0/.

\section{References}

1. Torre LA, Bray F, Siegel RL, et al. Global cancer statistics, 2012. CA Cancer J Clin 2015;65:87-108.

2. Bosetti C, Malvezzi M, Chatenoud L, et al. Trends in colorectal cancer mortality in Japan, 1970-2000. Int J Cancer 2005;113:339-41.

3. van der Stok EP, Spaander MCW, Grünhagen DJ, et al. Surveillance after curative treatment for colorectal cancer. Nat Rev Clin Oncol 2017;14:297-315.

4. Nicholson BD, Shinkins B, Pathiraja I, et al. Blood CEA levels for detecting recurrent colorectal cancer. Cochrane Database Syst Rev 2015;(12):CD011134.

5. Lech G, Słotwiński R, Słodkowski M, et al. Colorectal cancer tumour markers and biomarkers: Recent therapeutic advances. World J Gastroenterol 2016;22:1745-55.

6. Stelzner S, Hellmich G, Koch R, et al. Factors predicting survival in stage IV colorectal carcinoma patients after palliative treatment: a multivariate analysis. J Surg Oncol 2005;89:211-7.

7. Tebbutt NC, Norman AR, Cunningham D, et al. Intestinal complications after chemotherapy for patients with unresected primary colorectal cancer and synchronous metastases. Gut 2003;52:568-73.

8. Sun K, Chen S, Xu J, et al. The prognostic significance of the prognostic nutritional index in cancer: a systematic review and meta-analysis. J Cancer Res Clin Oncol 2014;140:1537-49.

9. Kruk J, Aboul-Enein HY. Reactive Oxygen and Nitrogen Species in Carcinogenesis: Implications of Oxidative Stress on the Progression and Development of Several Cancer Types. Mini Rev Med Chem 2017;17:904-19.

10. Wu R, Feng J, Yang Y, et al. Significance of Serum Total Oxidant/Antioxidant Status in Patients with Colorectal Cancer. PLoS One 2017;12:e0170003.

11. D'Arena G, Vitale C, Perbellini O, et al. Prognostic relevance of oxidative stress measurement in chronic lymphocytic leukemia. Eur J Haematol 2017;99:306-14.

12. Fujishita T, Okamoto T, Akamine T, et al. Association of
MTH1 expression with the tumor malignant potential and poor prognosis in patients with resected lung cancer. Lung Cancer 2017;109:52-7.

13. Sugimoto K, Takahashi R, Ishiyama S, et al. Analysis of the effects of alleviating adverse events and improving completion in colorectal cancer patients with postoperative adjuvant chemotherapy with PSK. Juntendo Medical Journal 2012;5:422-30.

14. Benson AB 3rd, Schrag D, Somerfield MR, et al. American Society of Clinical Oncology recommendations on adjuvant chemotherapy for stage II colon cancer. J Clin Oncol 2004;22:3408-19.

15. Cesarone MR, Belcaro G, Carratelli M, et al. A simple test to monitor oxidative stress. Int Angiol 1999;18:127-30.

16. Trotti R, Carratelli M, Barbieri M. Performance and clinical application of a new, fast method for the detection of hydroperoxides in serum. Panminerva Med 2002;44:37-40.

17. Schieber $M$, Chandel NS. ROS function in redox signaling and oxidative stress. Curr Biol 2014;24:R453-62.

18. Sosa V, Moliné T, Somoza R, et al. Oxidative stress and cancer: an overview. Ageing Res Rev 2013;12:376-90.

19. Pani G, Galeotti T, Chiarugi P. Metastasis: cancer cell's escape from oxidative stress. Cancer Metastasis Rev 2010;29:351-78.

20. Martinez-Useros J, Li W, Cabeza-Morales M, et al. Oxidative Stress: A New Target for Pancreatic Cancer Prognosis and Treatment. J Clin Med 2017. doi: 10.3390/ jcm6030029.

21. Vurusaner B, Poli G, Basaga H. Tumor suppressor genes and ROS: complex networks of interactions. Free Radic Biol Med 2012;52:7-18.

22. Bishayee K, Khuda-Bukhsh AR, Huh SO. PLGAloaded gold-nanoparticles precipitated with quercetin downregulate HDAC-Akt activities controlling proliferation and activate p53-ROS Crosstalk to Induce Apoptosis in Hepatocarcinoma Cells. Mol Cells 2015;38:518-27.

23. Sabharwal SS, Schumacker PT. Mitochondrial ROS in cancer: initiators, amplifiers or an Achilles' heel? Nat Rev Cancer 2014;14:709-21.

24. Hiraga R, Kato M, Miyagawa S, et al. Nox4-derived ROS signaling contributes to TGF- -induced epithelialmesenchymal transition in pancreatic cancer cells. Anticancer Res 2013;33:4431-8.

25. Zhang C, Cao S, Toole BP, et al. Cancer may be a pathway to cell survival under persistent hypoxia and elevated ROS: a model for solid-cancer initiation and early development. 
Int J Cancer 2015;136:2001-11.

26. Afanas'ev I. Reactive oxygen species signaling in cancer: comparison with aging. Aging Dis 2011;2:219-30.

27. Cornelli U, Terranova R, Luca S, et al. Bioavailability and antioxidant activity of some food supplements in men and women using the D-Roms test as a marker of oxidative stress. J Nutr 2001;131:3208-11.

28. Kilk K, Meitern R, Härmson O, et al. Assessment of oxidative stress in serum by d-ROMs test. Free Radic Res 2014;48:883-9.

29. Alberti A, Bolognini L, Macciantelli D, et al. The radical cation of N,N-diethyl-para-paraphenylendiamine: a possible indicator of oxidative stress in biological samples. Res Chem Intermed 2000;26:253-67.

30. Colombini F, Carratelli M, Alberti A. Oxidative stress, d-ROMs test, and ceruloplasmin. Free Radic Res 2016;50:447-53.

31. Ishizaka Y, Yamakado M, Toda A, et al. Relationship between serum uric acid and serum oxidative stress markers in the Japanese general population. Nephron Clin Pract 2014;128:49-56.

32. Kitano D, Takayama T, Nagashima K, et al. A comparative study of time-specific oxidative stress after acute myocardial infarction in patients with and without diabetes mellitus. BMC Cardiovasc Disord 2016;16:102.

33. Tsukioka T, Nishiyama N, Iwata T, et al. Preoperative serum oxidative stress marker as a strong indicator of nodal involvement in clinical stage I lung adenocarcinoma. Int J Clin Oncol 2012;17:250-5.

34. Katsabeki-Katsafli A, Kerenidi T, Kostikas K, et al. Serum vascular endothelial growth factor is related to systemic oxidative stress in patients with lung cancer. Lung Cancer 2008;60:271-6.

35. Baba Y, Sonoda JI, Hayashi S, et al. Reduction of oxidative stress in liver cancer patients by oral green tea polyphenol tablets during hepatic arterial infusion chemotherapy. Exp Ther Med 2012;4:452-8.

36. Ito K, Yano T, Morodomi Y, et al. Serum antioxidant capacity and oxidative injury to pulmonary DNA in never-smokers with primary lung cancer. Anticancer Res 2012;32:1063-7.

37. Komatsu F, Kagawa Y, Sakuma M, et al. Investigation of oxidative stress and dietary habits in Mongolian people, compared to Japanese people. Nutr Metab (Lond) 2006;3:21.

38. Jose C, Bellance N, Rossignol R. Choosing between glycolysis and oxidative phosphorylation: a tumor's dilemma? Biochim Biophys Acta 2011;1807:552-61.
Cite this article as: Sugimoto K, Sakamoto K, Kawai M, Kawano S, Munakata S, Ishiyama S, Takahashi M, Kojima Y, Tomiki Y. Serum oxidative stress is an independent prognostic marker in colorectal cancer. Transl Cancer Res 2019;8(5):16991708. doi: 10.21037/tcr.2019.08.15 